\title{
A criação do Museu Paulista na correspondência de Hermann von Ihering (1850-1930)
}

\section{Maria Margaret Lopes \\ Silvia Fernanda de Mendonça Figueirôa}

Depto. de Geociências Aplicadas ao Ensino/IG-UNICAMP

Rio Grande do Sul, 13 de junho de 1892

[... Em quanto a mim eu algum tempo tinha a esperança que Berg me vae fazer seu sucessor em Montevideo, mas como elle nada me escreveu, parece que elle tem outros que prefere, embora que elle sempre está em correspondencia amigavel commigo. Digame que rendimento dá a Directoria do Museu em Montevidéo calculada em moeda ingleza ou franceza; será isso mais que se preciza lá para a vida? Offereceram-me fazerme lente cathedratico para a faculdade de Medicina que se vae fazer em São Paulo mas não creio que aceito e que vou vêr dirigir ali Frenzel. Ao contrario desejo uma Directoria de Museu se ella fôr bem paga. Em Porto Alegre para tal fim contam commigo, mas aqui tudo anda incerto pela política. Tudo isso entre nós, mas desejo suas informações [...] Hermann von lhering a Florentino Ameghino (TORCELLI, 1935, p. 179).

As correspondências entre cientistas, de caráter privado ou público, longe de se constituírem no que, à primeira vista, poderia ser considerado como mera documentação burocrática ou administrativa, merecem ser investigadas em níveis mais sofisticados. Na História das Ciências, uma longa tradição de edição e comentários da correspondência recebida e/ou emitida por diversas personalidades do mundo das ciências e das técnicas se mantém viva até hoje, em projetos que chegam a envolver dezenas de pesquisadores - como no caso das cartas de Charles Darwin depositadas na Universidade de Cambridge. Já em 1975, um simpósio discutiu, especificamente, questões teóricas, práticas e de método ligadas a essa fonte?, imprescindível para a compreensão da construção das ciências em toda a sua complexidade. Como afirma Dibon (1976, p. 47):

\author{
1 "Les correspondances: \\ leur importance pour \\ l'historien des Sciences et \\ de la Philosophie. \\ Problèmes de leur \\ édition." Journées de \\ Chantilly, 5-7 Mai 1975. \\ Textos publicados na \\ Révue de Synthèse, Tomo \\ XCVII, n.81-82, Jan-jun \\ 1976
}

As correspondências oferecem, portanto, ao historiador, uma mina de informações de todos os tipos: acontecimentos políticos, militares, fatos os mais diversos, rivalidades pessoais, polêmicas, discussões filológicas, argumentações teológicas, trocas de observações ou de experiências científicas, novidades das livrarias, novidades universitárias, etc. (...) E forçoso constatar, todavia, que o mineral precioso está freqüentemente envolto numa ganga, da qual só se pode extraílo após grande esforço. 
(...) Convém, para aquilatar o valor documental, reinseri-las num diálogo e, se possível, mantê-lo em paralelo a outros diálogos conduzidos pela mesma personalidade com interlocutores diversos.

Outram (1980), em suas análises sobre a correspondência de Cuvier, sugeriu que embora as cartas tenham uma massa de fatos e detalhes de valor inestimável para o historiador que procura reconstruir a complexidade dos eventos e das situações, elas também tinham em si funções positivas, complexas e mutáveis cujo mapeamento é vital para nossa compreensão do meio que as gerou e seu lugar nesse meio. As cartas eram um importante veículo através do qual interessados de diferentes ordens abriam seu caminho no mundo das ciências e das relações internacionais, seja buscando emprego para si, ou para algum conhecido; conquistando status diante de um colega e/ou eventual colaborador, checando informações antes de suas publicações, etc. Tratava-se de estratégias de afirmação pessoal e institucional, constituindo uma privilegiada forma de sociabilidade e de consagração na comunidade científica (LOPES; FIGUEIRÔA, 2002).

Ao trazer para a análise histórica aspectos que, ao longo dos séculos, foram sendo cada vez mais expurgados da comunicação pública da ciência, as correspondências permitem redimensionar o próprio conceito daquilo que se chama "ciência" - isto é, algo bem mais amplo do que um certo corpo de conhecimentos. Permitem, sem dúvida, suavizar esquemas interpretativos simplificadores - e muitas vezes, reducionistas - incorporando personagens de carne e osso e o "reverso" da história.

$\bigcirc$ Museu Paulista tem redespertado o interesse de historiadores e historiadores das ciências: Alves (1998), Brefe (1999), Elias (1 996), Figueirôa (1992), Gualtieri (2001), Lopes (1993), entre outros, para não mencionarmos os trabalhos de referência obrigatória de Ulpiano B. de Meneses. Múltiplos aspectos de sua trajetória institucional têm sido investigados, as diretrizes políticas propostas por seus diretores têm sido analisadas, e a vasta documentação relacionada à instituição tem revelado aspectos inusitados dos diferentes momentos conjunturais porque passou esse Museu, primeiro de História Natural e depois de História de São Paulo. Assumindo enfoques e ênfases diferenciados, interpretações sugeridas nem sempre coincidentes, a maioria desses trabalhos não contemplou com maior profundidade, seja por seu enfoque temático, ou por outro motivo, nem Hermann von lhering, seu primeiro e um dos mais proeminentes diretores, nem tampouco fontes documentais mais particulares sobre o período em que o naturalista dirigiu a instituição, tais como a correspondência de lhering. No presente texto, focaremos a troca de cartas de lhering com Orville Derby e Florentino Ameghino, privilegiando o momento de criação do Museu.

As teses e dissertações mencionadas, por não considerarem a inserção latino-americana de thering e seu museu, deixaram de considerar inúmeros aspectos que podem nos permitir melhor compreensão de qual o sentido da instituição museal no período considerado. Por exemplo, a forma como lhering musealizou os princípios de Brown-Goode em que se apoiava, para cumprir o papel que cabia ao Museu Paulista como "meio de educação e de progresso da ciência" (IHERING, 1897, p. 6), permanece um tema insuficientemente considerado. Sem investigar mais a fundo como sua formação naturalista, sua especialização em moluscos fósseis e viventes, e suas concepções de ciências conduziram seu trabalho museológico em estreita conexão com os diretores e museus do Cone Sul, especialmente argentinos, seu ideal de museu sul-americano, sua pretensão à 
direção do Museu de Montevidéu, a doação de seus documentos e coleções ao Museu de Buenos Aires, a sindicância que acompanhou sua saída do Museu (RIBEIRO, 1916), permanecem incompreensíveis.

Um panorama institucional do período

Entendidos como locais de investigação, tanto no Brasil como na Argentina e no Uruguai, aos museus do final do século XIX não coube a responsabilidade de dar aulas. Atividades a que Hermann Burmeister e Florentino Ameghino (diretores do Museu de Buenos Aires entre 1862 e 1912) se recusaram em todas as oportunidades possíveis, uma vez que os desviava de suas funções prioritárias de investigações. Aliás, por ter aceitado dar aulas no Colégio de Buenos Aires, Carlos Berg que sucederia a Burmeister na direção do Museu argentino, foi obrigado a renunciar a seu posto de inspetor público do Museu, cargo para o qual o velho diretor Burmeister considerava fundamental a dedicação integral.

A dedicação exclusiva à pesquisa foi também um dos aspectos característicos dos processos que transformaram as ciências em ocupação profissional (BARNES, 1987). Foi uma das tônicas do processo de profissionalização também dos naturalistas brasileiros e que a administração de Ladislau Netto inaugurou no Museu Nacional do Rio de Janeiro. À diferença dos antigos diretores do Museu Nacional - médicos ou engenheiros, professores das escolas da Corte, parcialmente dedicados ao Museu -, Ladislau Netto e seus sucessores foram obrigados, a partir de 1876, à dedicação exclusiva, seus funcionários submetidos a concursos de admissão, e necessitavam de autorizações especiais para se dedicarem a outras atividades, desde que estas não prejudicassem seus trabalhos no Museu.

Os processos de consolidação das ciências naturais nos meados do século no Brasil podem ser lidos - preservadas as necessárias distâncias -, como inseridos nos horizontes do que Turner (1980) consagrou como "ciência pública". Numerosos estudos nas últimas décadas vêm estabelecendo firmemente que o conteúdo intelectual, a orientação metodológica e a organização profissional da ciência não se dissociam de seu ambiente social e cultural. Os "cientistas" de hoje e de ontem continuam a fazer parte de uma ordem social mais ampla, que os leva a justificar suas atividades junto aos poderes políticos e outras instituições sociais, de cujas políticas, boa vontade, mecenato e cooperação dependem. Com esse entendimento, a ciência pública é proposta como o corpo de retórica, argumentos e polêmicas produzido nesse processo social, considerando aqueles que sustentam esse empreendimento como cientistas públicos.

Turner divide a carreira da ciência pública britânica em dois períodos anteriores a 1870: o do começo do século XIX, até aproximadamente a Grande Exibição de 1851, e o da metade dos anos 1840 até o fim de 1870, que caracteriza como a era da ciência pública vitoriana:

[...] os grandes divulgadores científicos vitorianos, entre outros, empregaram as teorias de evolução, atomismo, e a conservação de energia como instrumentos para desafiar a dominância cultural dos clérigos, para atacar a religião e a metafísica no pensamento científico, e para forjar uma comunidade cientifica profissional genuinamente autoconsciente baseado na ciência perseguida segundo premissas estritamente naturalistas. 
Para Turner, o início dos anos 1870 foram anos de verdadeira expectativa profissional para a comunidade científica, que começava a se autodefinir, a se tornar uma comunidade independente, reconhecida como tal por outros grupos intelectuais e profissionais:

estado havia por algum tempo consultado especialistas científicos em uma base ad hoc e estava começando a empregar alguns cientistas no serviço público e nas diretorias consultivas administrativas. A reforma do sistema educacional após 1870 parecia prometer nova influência e emprego na ciência (TURNER, op. cit., p. 591).

A mesma tônica em termos de periodização e profissionalização se encontra em textos analíticos sobre a organização da ciência e da tecnologia na França do século XIX. Fox e Weisz (1980) consideram que o modelo vigente e a historiografia dominante sobre a educação científica francesa no século XIX necessitam de maiores explicações. Analisam o que entendem como um movimento de reforma, de 1863 a 1914, e apontam que, por volta da década de 1860, a "profissionalização" dos acadêmicos era, mesmo segundo os padrões franceses, muito pouco desenvolvida em virtude do grau de dispersão dos cinco diferentes tipos de faculdades existentes.

Separados ainda mais por divisões regionais e hierárquicas, o corpo docente tinha grande dificuldade em se unir por objetivos comuns. Essa fraqueza, junto com uma noção um tanto diluída do que era o comportamento adequado para os funcionários de elite, impedia os reformadores acadêmicos (ao contrário dos médicos e farmacêuticos, por exemplo) de fundar associações corporativas que defendessem abertamente seus interesses profissionais.

Coincidências de temporalidades estão longe de ser suficientes para aproximar quadros teóricos interpretativos. E nossa intenção aqui não é essa. Se, evidentemente, os quadros referenciais são outros, embora os problemas mencionados em outras conjunturas sejam familiares aos historiadores das ciências do século XIX, também no Brasil os marcos temporais coincidentes com aqueles empregados em tentativas de periodização das práticas científicas no país sugerem alguma reflexão. Ao buscarmos marcos referenciais de contextualização dos ambientes de sociabilidade e profissionalização a que nossos naturalistas do meados do XIX tinham acesso - por formação e/ ou informação e participação, mas a que seguramente almejavam por inspiração -, não fazemos mais do que apontar perspectivas futuras de investigação, sugeridas por nossas pesquisas atuais.

A pretensão e as expectativas de von thering de se tornar diretor de um Museu

Após 1870, grosso modo, museus agrícolas, de indústria e comércio, e particularmente de História Natural proliferaram largamente, seguindo os modelos traçados pelos museus que se criaram em função, ou a partir das grandes Exposições Universais. Esse "movimento de museus", por outro lado, também integrou o movimento de museus em nível internacional, caracterizado por Laurence Vail Coleman - diretor da American Association of Museums - como um verdadeiro movimento social, marcado pelo estabelecimento de uma vasta rede de intercâmbios 
que pôs em contato, segundo dinâmicas variadas, os museus que foram se criando pelos quatro cantos do mundo.

No que toca aos antigos museus de História Natural que se renovavam, ou aos novos que se criavam, as mudanças de paradigmas pelas quais passavam as Ciências Naturais, Etnográficas e Antropológicas, a partir da segunda metade do século XIX, tiveram papéis determinantes. As coleções, gabinetes e os museus relacionados a essas ciências passaram a ganhar relevância também no Brasil, no contexto das idéias positivistas e evolucionistas que marcaram esse período. Como em todo o mundo, o interesse despertado pelas ciências naturais - que ainda englobavam a Antropologia, a Arqueologia e a Etnografia -, e pela busca das origens do homem americano esteve na base da organização de diversas coleções particulares também no Brasil e em São Paulo. Coleções estas ainda não investigadas e das quais existem algumas pistas, e que conviveram e colaboraram com as iniciativas oficiais implementadas.

Algumas dessas coleções foram abertas a algum tipo de público como a de Miguel Dutra, em Piracicaba - e receberam elogios de seus visitantes. Em 1889, Orville Adalbert Derby (1 851 -1915), geólogo norte-americano radicado no Brasil desde 1875 e então chefe da Comissão Geográfica e Geológica de São Paulo (CGG), a fazer um retrospecto dos trabalhos geográficos e geológicos realizados na Província de São Paulo, destacava a importância científica de amostras das coleções particulares paulistas, e afirmava que:

Ocupa o primeiro lugar dentre estes gabinetes [de História Natural] o do coronel Joaquim Sertório, que já pode ter o nome de museu, onde, mesmo com exame ligeiro, tenho colhido alguns fatos importantes sobre a geologia da Província (DERBY, 1889).

Em 1895, na abertura do primeiro número da Revista do Museu Paulista, foi reproduzido um ofício do mesmo Orville Derby, datado de 29/8/1895, no qual relatava as origens do Museu Paulista:

[...] tendo em fins de 1890 o sr. Conselheiro Mayrink adquirido o prédio situado no Largo Municipal construído pelo Cel. Sertório para sua residência e para acomodar a coleção que tinha acumulada e que era geralmente conhecida pelo nome de "Museu Sertório", e estando a dita coleção incluída na compra do Conselheiro Mayrink, esta foi oferecida em seu nome ao Governo do Estado em 23/12/1890. Retirando-se o Cel. Sertório da casa, esta ficou fechada, e durante alguns meses o Governo do Estado nenhuma providência tomou sobre a dádiva que tinha recebido².

Finalmente compradas pelo conselheiro Francisco de Paula Mayrink, as coleções do Museu Sertório foram acrescidas de materiais do Museu Provincial da Associação Auxiliadora do Progresso de São Paulo e do acervo de um outro colecionador particular, sempre referido nos documentos como Pessanha, além das pertencentes ao próprio von Ihering, e no conjunto constituíram o acervo inicial do Museu Paulista.

Graças aos esforços do botânico da CGG, o sueco Alberto Löfgren, em abril de 1891 o governo estadual autorizou uma pequena verba para a conservação desse conjunto de coleções, que ficaram sob a coordenação de Löfgren auxiliado por dois preparadores, Guilherme Friedenreich e Alexandre Hummel. Em dezembro de 1892, as coleções foram removidas para uma casa no Largo do Palácio (hoje Pátio do Colégio) e, em março de 1893, para a sede da CGG - à qual foram anexadas assim como o pessoal. Segundo Derby, a
2. Ofício de Orville A. Derby, chefe da CGG, a Hermann von Ihering, diretor do Museu Paulista. São Paulo, 29/8/1895. ass. Revista do Museu Paulista, T. I, p. 13-15, 1940 (reedição). 
3. Idem ibidem, p.14-5

4. Uma primeira notícia dessas cartas foi dada em: Figueirôa, S. F. de M.. The writings of Orville Adelbert Derby (18511915) and its meaning to the history of geological sciences in Brasil. In: INT. SYMP. HIST. OF GEOL. SCIENCES, 16, 1991 Dresden. Abstracts... Dresden, INHIGEO, 1991, p. 19-20.

5.A correspondência entre os dois naturalistas se encontra noArchivo de la Secretaria del Museo Argentino de Ciencias Naturales, Buenos Aires, Carpeta Ihering Ameghino.A sua saída do Museu Paulista, Ihering doou sua correspondência ao Museu argentino e acompanhou diversos aspectos de sua edição. Maria Margaret Lopes consultou essa documentação e tem sistematicamente tratado essa correspondência no âmbito do projeto: Contribuição à História da Museologia na América Latina: as redes de comunicação estabelecidas pelos museus (1870-1914), que conta com o apoio do CNPq (2002-2004)

6. Ver a propósito desses temas o artigo de Lopes e Figueirôa (1994). precariedade da situação do Museu Sertório começaria a ser minimizada a partir desse momento, quando foi anexado à Comissão Geográfica e Geológica. Conforme sua versão pública ${ }^{3}$,

[...] esbocei um plano para o coordenar e desenvolver modestamente à sombra da Comissão Geográfica e Geológica, que tinha a seu cargo diversos serviços que podiam contribuir para várias seções de um Museu de História Natural [...]. Sendo-me oferecida a cooperação de um zoologista de grande nomeada [Hermann von Ihering], aproveitei o ensejo para completar o programa de um verdadeiro museu propondo ao governo a criação de uma seção zoológica nesta Comissão - proposta que foi aceita [...] [e que] foi iniciada em maio de 1893. Logo depois o Congresso do Estado determinou criar no monumento do lpiranga um museu independente, e no princípio do exercício de 1894 cessou a ligação provisória do Museu com a Comissão Geográfica e Geológica, passando para o novo estabelecimento o pessoal da seção zoológica desta.

Havia, porém, uma realidade muito mais palpitante por detrás das palavras oficiais, que vale ser apresentada e discutida. Felizmente, nesse caso específico preservaram-se os detalhes das negociações na correspondência mantida entre Derby e von thering de 29/1/1886 a 17/1/1915 - 109 cartas escritas pelo primeiro e recebidas pelo segundo, hoje arquivadas na Seção de Manuscritos da Staatsbibliotek Preussischer Kulturbesitz em Berlim ${ }^{4}$, além dos complementos presentes na correspondência entre von Ihering e Florentino Ameghino5.

Hermann von Ihering entregou ao Museu de Buenos Aires, juntamente com sua coleção de moluscos, os originais das cartas de Florentino Ameghino que possuía. Documentos fundamentais para a história da Geologia e Paleontologia cenozóica Argentina, merecedores de um estudo à parte 6 , essas cartas são reveladoras do processo de cooperação que se estabeleceu entre os dois naturalistas de 1890 a 1911 . Nesse caso específico, é importante ressaltar que, - por se tratarem de museus, quer o Museu Paulista, quer o Museu de Buenos Aires e de naturalistas, tanto Hermann von Ihering como Florentino Ameghino, que definiam acima de tudo a vocação científica de suas instituições -, suas inserções no movimento de museus se deram fundamentalmente pela via das práticas científicas características desses museus à época, quais sejam: a troca de coleções e informações para classificação, organização e publicação de artigos científicos. Esta é a tônica do conjunto da correspondência dos dois naturalistas, permeada evidentemente por uma soma de questões institucionais, políticas, e especialmente de aspectos das vidas particulares dos dois naturalistas que se tornaram amigos, trocaram fotos suas e das famílias antes de se conhecerem e discutiram suas situações profissionais.

Hermann von Ihering (1 850-1930) chegou ao Brasil em 1880, e foi a princípio interessado em Antropologia Física (craniometria). Foi naturalista-viajante do Museu Nacional do Rio de Janeiro até 1891, e seus estudos abrangeram as mais diversas áreas da História Natural, tendo deixado publicações botânicas, antropológicas e etnológicas, dedicando-se porém, ao longo de toda sua a vida, desde sua tese de doutorado, à Zoologia e Paleozoologia de moluscos. Considerado um notável malacólogo, era também uma autoridade em outros ramos da Zoologia e dedicava-se ainda à Etnografia. Dando conta de sua inserção internacional, Ihering apresentava-se na capa do Museu Paulista como sócio honorário da Sociedade Antropológica Italiana, da Academia de Ciências de Córdoba, da Sociedade Geográfica de Bremen, da Sociedade Antropológica de Berlim, da Academia de Ciências da Filadélfia, da Sociedade de Naturalistas 
de Moscou, da Sociedade Entomológica de Berlim, do Museu Etnológico de Leipzig e da Sociedade Científica do Chile.

$\bigcirc$ início da correspondência entre Derby e von lhering deu-se pouco antes do primeiro começar a chefiar a CGG, estando von thering no Rio Grande do Sul, pela leitura de um artigo deste último sobre a Lagoa dos Patos, que Emil Göldi emprestara a Derby ${ }^{7}$. Manteve-se neste patamar principalmente técnicocientífico por algum tempo, com troca de fósseis (sobretudo conchas), minerais e artigos científicos. Derby, inclusive, após ter tomado conhecimento das idéias de von lhering a respeito de pretéritas ligações entre os continentes sul-americano e africano, remeteu-lhe um artigo de um certo "Dr. Waagen" a respeito ${ }^{8}$.

A propósito, é oportuno destacar que Hermann von lhering está entre os predecessores da Teoria da Deriva Continental: em 1907 publicou um livro, "Archhelenis \& Archinotis", no qual, baseado em intensa pesquisa paleontológica em diferentes coleções de fósseis brasileiros e sul-americanos, desenvolveu uma teoria admitindo antigas conexões entre a América do Sul, a Africa e a Antártica que se teriam perpetuado até o Plioceno. Archhelenis teria sido um continente formado pela América Meridional e a África, e Archinotis, pela parte sul da América do Sul e a Antártica. As raízes desta teoria podem ser rastreadas em Eduard Suess (1831-1914) e nas idéias a respeito da fragmentação da crosta terrestre (GOHAU, [s.d.])

A significância do trabalho de von Ihering para a Teoria da Deriva Continental pode ser atestada pelo fato de suas idéias e seu livro terem sido citados desde a primeira edição de Die Entstehung der Kontinente und Ozeane, de Alfred Wegener, o proponente da teoria, tendo inclusive um de seus mapas reproduzidos (LOPES; FIGUEIRÔA, 1990).

Sobre a criação do Museu Paulista, Derby explicitou seu plano em uma carta de 12/10/1892, convidando von Ihering para dirigi-lo:

\footnotetext{
[...] estou pensando em propor ao governo do estado daqui a criação de uma seção Zoológica da Comissão com responsabilidade sobre o Museu para ser oferecida a você. [...] Presumo que a coisa possa ser arranjada mas não estou certo. Isto o agradaria no caso de poder ser feito? Por favor, telegrafe-me sim ou não no recebimento desta. ${ }^{9}$ (grifos do autor).
}

Ihering certamente aceitou a proposta, pois Derby respondeu dando conta dos próximos passos:

[...] como nossa nova verba, que foi consideravelmente aumentada, estará disponível no início do ano, está acertado que no próximo mês eu devo propor a reorganização da Comissão, na qual devo propor a criação de uma Seção Zoológica tendo você na chefia. Tenho a certeza [de que] a sugestão será favoravelmente considerada e tenho pouca dúvida de que não seja aceita. ${ }^{10}$ (grifos do autor).

Pelas cartas subseqüentes, parece entretanto que von thering não estava plenamente satisfeito com a proposta, desejando algo mais ambicioso: em vez de um cargo de "chefe da seção zoológica com a coordenação do Museu", Ihering almejava ser "Diretor do Museu" já desde o início. E Derby, por seu turno, exprimia privadamente a opinião que não emitira em público:

\begin{abstract}
7. Carta de Orville Derby a Hermann von Ihering (em inglês). Rio de Janeiro, 29/01/1886. STAATSBIBLIOTEK PREUSSISCHER KULTURBESITZ, Berlim, Hand-schriftenabteilung,Darmm.Smlg., La 1892, (15).

8. Carta de Orville Derby a Hermann von Ihering (em inglês).São Paulo, 29/ $0 \quad 1 / 18892$ STAATSBIBLIOTEK P R E U S S I S C H E R KULTURBESITZ, Berlim, Hand-schriftenabteilung, Darmm. Smlg., La 1892, (15).
\end{abstract}

9. Carta de Orville Derby a Hermann von Thering (em inglês). São Paulo, 12/10/ 1892. STAATSBIBLIOTEK P R E U S S I S C H E R KULTURBESITZ, Berlim, Hand-schriftenabteilung, Darmm. Smlg., La 1892, (15).

10.Carta de Orville Derby a Hermann von Ihering (em inglês). São Paulo, nov. 1892. STAATSBIBLIOTEK PREUSSISCHER KULTURBESITZ, Berlim, Hand-schriftenabteilung, Darmm. Smlg., La 1892, (15).

Quanto ao Museu está muito melhor atualmente e está temporariamente abrigado numa casa particular. É uma coleção de curiosidades que foi presenteada ao Estado e que tem pequeno valor científico, exceto como um alicerce para se construir alguma coisa 
11. Cartas de Orville Derby a Hermann von Ihering (em inglês). São Paulo, 23/11/1892 e 16/ 0
0 STAATSBIBLIOTEK P R E U S S I S C H E R KULTURBESITZ, Berlim, Hand-schriftenabteilung, Darmm. Smlg., La 1892, (15)

12. Carta de Orville Derby a Hermann von Ihering (em inglês). São Paulo, 16/1/1893. S TAATS BIBLIOT EK P R E U S S I S C H E R KULTURBESITZ, Berlim, Hand-schriftenabteilung, Darmm. Smlg., La 1892, (15).

13. Carta de Orville Derby a Hermann von Ihering (em inglês).São Paulo, 23/ $1 / 1893$ STAATS BIBLIOTEK P R E U S S I S C H E R KULTURBESITZ, Berlim, Hand-schriftenabteilung, Darmm. Smlg., La 1892, (15).As palavras entre aspas estão em português no texto original em inglês. no futuro. Ele é tão insignificante, entretanto, que meus planos eram fazer de você o chefe da Seção de Zoologia, encarregado do Museu, que só depois pode conseguir importância suficiente para ser independente. [...] A Comissão pode fornecer infraestrutura para trabalhos zoológicos, para os quais, no momento, você não encontrará em nenhum lugar do Brasil, e um decente salário [...]. A menos que você me diga o contrário, devo continuar tratando da criação dessa seção de Zoologia ${ }^{1}$.

\section{Derby continuaria a informar thering do andamento das negociações e} esclareceria ainda mais:

Estou agora autorizado a nomear um zoólogo para a Comissão com um salário e $700 \$ 000$ por mês [...]. Como o Museu é pouco importante e está atualmente ligado à Comissão, pensei que isto é melhor [...] dado que tenho mais liberdade quanto à verba na Comissão do que se pode ter no Museu per si. [...] Quanto às suas coleções, não tenho dúvida de que, se trazidas para São Paulo, posso conseguir a compra para o Museu, pela soma que você disser, mais os custos de transporte. [...] no momento [o museu] é um assunto secundário, ou na verdade um pretexto para criar o posto de zoólogo para a Comissão, que lhe dará um salário e meios de trabalho para o estudo da fauna de São Paulo ${ }^{12}$

Como parece que von thering insistisse na direção de um Museu de pronto, Derby endereçou-lhe uma carta em 23/1/1893 na qual, em tom formal e chegando ao quase rompimento, desvenda completamente o caminho e as motivações que levaram à fundação do Museu Paulista, que apesar de longa citaremos quase na íntegra:

em primeiro lugar, o governo de São Paulo não está especialmente interessado nem em estudos zoológicos nem no museu, considerando este último mais bem como uma espécie de elefante branco [... uma opinião com a qual eu intimamente concordo. Ele consiste de uma coleção privada feita por um "curioso" e vendida por ele junto com a casa para um rico especulador durante o "boom" [do café], o qual fez presente da coleção ao governo e ficou com a casa. $\bigcirc$ governo, não sabendo o que fazer com ela e não desejando incorrer em despesa, "encostou" o museu na Comissão, e eu muito relutantemente aceitei o encargo a fim de preservar o que havia de valor nas coleções e para manter viva a idéia de um museu, que no futuro poderá se transformar em algo melhor. [...] Quando apelos me foram feitos para arranjar algo para o senhor aqui em São Paulo, tomei a idéia do museu e do trabalho zoológico na Comissão como os meios práticos para fazer - que me haviam pedido a fim de ajudar um colega que se supunha necessitado de um tal serviço. $\bigcirc$ que propus foi tanto quanto pude, naquelas circunstâncias. [...] A autorização para nomear um zoologista [...] foi um sinal de consideração a mim, não um interesse no Museu ou em pesquisa zoológica. [...] Como o sr. vê, o lugar oferecido foi criado ad hoc para o senhor, e se não aceitá-lo nenhuma indicação será feita. Apenas três pessoas em todo São Paulo, Dafert, Löfgren e eu, sentiremos muito sua decisão, os outros não ligarão a mínima ao assunto, quer a favor ou contra. Não entrei antes nesses assuntos porque não desejava que viesse para cá com algum tipo de obrigação pessoal para comigo [...] mas [...] vi pelas suas cartas que compreendeu de forma absolutamente errônea a situação. Ficarei encantado se você decidir vir e nos dar a sua cooperação no trabalho científico de São Paulo, o único lugar em que mais de um indivíduo está tentando fazer alguma coisa em todo o Brasil. Se, ao considerar toda a problemática, você decidir aceitar, por favor telegrafe a palavra "recebido"13 (grifos nossos).

Complementos destas discussões encontram-se nas cartas trocadas entre von Ihering e Florentino Ameghino. Em janeiro de 1892, von lhering escreveu a Ameghino expressando suas opiniões sobre as mudanças políticas do País e suas implicações para as ciências locais. Dando sua versão sobre sua demissão e a de Fritz Müller do Museu Nacional do Rio de Janeiro "por simples chicanas do Diretor", explicita as funções que cabem ao naturalista e que tipo de apoio esperava para tal do Estado: 
A mudança do Governo no Brasil foi a desmoralização na administração e ciência; o colega o julga possível que o Museu Nacional do Rio de Janeiro com o seu orçamento de 80 contos por ano provavelmente o melhor dotado na América do Sul agora não possui um único naturalista! [...] No ano passado foi idéia me nomear [diretor da seção zoológica], mas eu não quis. Ao contrário fizeram um rescrito declarando que os naturalistas morando fora têm de mudar-se para o Rio [...]. O colega sabe bem que Müller, Goeldi e eu somos agora os únicos zoólogos em todo o vasto país do Brasil. Não o valia de pagar-nos o pequeníssimo ordenado que recebemos para que continuemos nas nossas investigações, útil decerto ao país? Não somos todos dois sábios conhecidos e respeitados no mundo científico e representando bem a ciência natural do Brasil? (TORCELLI, op.cit., p. 165)

Ainda sem emprego em junho de 1892, portanto antes do início dessa troca de cartas com Derby, von Ihering, radicado no Rio Grande do Sul, acompanhava com vivo interesse as movimentações do mercado de trabalho nos museus do sul da América. Na mesma carta em epígrafe, em que expressava sua expectativa em relação a um convite de Berg, e buscava se informar das condições econômicas do emprego, afirmava ao amigo que em sua opinião apenas Berg (então diretor em Montevidéu) e o próprio Ameghino se colocavam como possíveis sucessores de Burmeister, que acabara de morrer. Informava sobre outros interessados na sucessão e aconselhava Ameghino a fazer tudo "para que não ali venham outros que são seus inimigos!" Interessado nas possíveis alianças que se estabeleceriam, indagava sobre Berg: este penderia mais para Ameghino ou para Moreno? - Francisco Pascásio, então diretor do Museu de la Plata.

Von lhering receberia resposta da carta enviada a Ameghino somente em setembro de 1892:

Su carta del 15 de Junio, en la que me pedía informaciones sobre el sucesor de Burmeister y el Museo de Montevideo, llegó tarde, cuando ya hacía mucho que Berg habia sido nombrado Director del Museo de Buenos Aires y Arechavaleta del de Montevideo. No le contesté a V. inmediatamente, porque además de estar ocupado en asuntos urgentísimos, también estaba de mal humor y ni quería íir hablar de Museo, ni de Berg, ni de nada que con ellos tuviera relación (TORCELLI, op.cit., p. 183).

E Ameghino continuava informando que Berg havia "se portado de modo indigno" para com ele, recusando-se em aceitá-lo como vice-diretor do Museu de Buenos Aires.

Em resposta de 13 de fevereiro de 1893, von Ihering lamentava a desconsideração para com o paleontólogo argentino e sugeria estratégias para continuar a manter o acesso às coleções, comunicando-lhe sua decisão:

Sinto muito que V.S. não houve a II Directoria do Museu. V.S. agora deve trabalhar para que a, secção paleontológica do Museu fique separado da zoológica e será então para V.S. É escandaloso, que em quanto todo o mundo scientífico olha para as suas descobertas, a República Argentina the tira os meios de estudo!

"Quanto a mim aceitei a diretoria do Museu de São Paulo onde vou como chefe da secção zoológica da Commissão geographica-geologica. Vou em Maio. Infelizmente o Museu não existe - só que vou organizá-lo." Em tempo, ainda estabelecia os termos de seus acordos de trabalho, os quais à época de sua demissão do Museu the trariam enormes transtornos, sindicâncias, etc.: "O que em São Paulo aparecer em ossos de mamíferos, etc. será entregue a V.S. para estudo (se o meu chefe Derby, com o qual bem me dou, consinta) como tudo á de conchas fósseis será para mim" (TORCELLI, op.cit., p. 183-184). 
14. Regulamento do Museu Paulista, artigo $2^{\circ}$, 1894
Ihering teve que finalmente aceitar as condições de Derby, pelo menos a princípio. Uma vez constituída a Seção Zoológica da Comissão Geográfica e Geológica de São Paulo, logo no ano seguinte o Museu Paulista tornar-se-ia uma instituição autônoma e lhering o dirigiria por 22 anos (1894-1915). Mas nesse primeiro ano as dificuldades foram muitas, contava von thering a Ameghino em setembro de 1893:

Faz tempo que não the escrevo! Chegando aqui entrei em posição insuportável e custou-me muito obter a reorganização do Museu a que agora se está procedendo. Felizmente realizou-se isto - mas que desgostos, que trabalho até lá. O amigo entenderá, que neste tempo não quis escrever [...] O primeiro trabalho que aqui fiz foi a determinação das conchas marinas das pampas. Correspondem aos do Sul do Brasil e Uruguai, facies modernas. Vou publicar a lista nos meus Archivos [...] Em breve terei mudança de Museu que vae ao esplendido monumento do Ypiranga, que só tem o defeito de ser situado um pouco longe, fora da cidade. Vou ter pessoal suficiente, fazer publicações, afinal ganhei a partida (TORCELLI, op.cit., p. 187).

Hermann von Ihering, que não ambicionara só um Museu provincial, começou a construir seu sonho de um Museu Sul-americano, em função de seus próprios trabalhos de dimensões continentais. Como já mencionamos, ele era adepto da teoria das pontes continentais, e demonstrou suas hipóteses com base nos estudos das coleções de moluscos que reuniu no Museu Paulista e que classificou para os museus argentinos, chilenos, australianos e neozelandeses. O Regulamento do Museu Paulista não deixava margem a dúvidas quanto a esses interesses:

caráter do Museu em geral será o de um Museu Sul-Americano, destinado ao estudo do reino animal, de sua história Zoológica e da História Natural e cultural do homem. Serve o Museu de meio de instrução pública e também de instrumento científico para o estudo da natureza do Brasil e do Estado de São Paulo, em particular ${ }^{14}$.

Na mesma perspectiva, e já de seu posto de diretor, von lhering divulgava os trabalhos de seus pares estreitando seus elos de cooperação e, insinuando suas críticas ao Museu Nacional brasileiro (LOPES, 1997), apresentava os "Anales del Museo de Montevideo" na "Revista do Museu Paulista" com as seguintes palavras elogiosas:

primeiro número desta nova publicação já nos deixa reconhecer que está na altura de uma revista moderna dedicada ao estudo da historia natural de sua pátria. Será, pois, mais um passo no desenvolvimento científico da América do Sul, e assim damos os nossos parabéns ao diretor daquele estabelecimento, que por decênios achou-se no estado ridículo de muitos museus sul-americanos, que é afinal o estado de cada Museu administrado por pessoas de influência local e não por pessoas formadas e dedicadas às ciências. Foi no ano de 1890 que o célebre Carlos Berg, atual diretor do Museu Nacional de Buenos Aires, foi incumbido da direção daquele instituto [...]. A direção do Dr. Berg foi de pouco tempo, mas bastava para dar ao Museu de Montevideo o seu atual cunho, o seu caráter científico. É de sumo interesse comparar nas diversas repúblicas da América do Sul o caráter dos Museus e dos outros institutos científicos. Uns, são dirigidos por celebridades nacionais incapazes, simplesmente caricaturas, e outros se põem ao lado dos melhores de Europa e da América do Norte.

Pensamos que este documento é um testemunho de excepcional importância para uma compreensão mais ampla da história dos processos de institucionalização das ciências naturais no Brasil, bem como da contribuição dos museus a estes processos. Pelos estudos já acumulados até o presente, é unânime a constatação do papel que o Estado desempenhou na promoção de atividades 
científicas, principalmente através da criação de loci institucionais. No entanto, ao lado desse papel principal, existiu um outro, de não menos importância, acionado pela própria comunidade científica da época: o de abrir espaço a iniciativas claramente pessoais e individuais de cientistas que buscavam a segurança de espaços institucionais que lhes garantissem salário e suporte (financeiro e de infra-estrutura) para a realização de suas pesquisas e a construção de suas carreiras científicas. Salientamos a importância de se considerar o peso das posições individuais, particularmente nesse episódio, porque além de ignoradas em diversas histórias oficiais, tais posições nos ajudam a melhor compreender o contexto em que se viabilizaram algumas - e não outras -, instituições científicas paulistas, dentre elas os museus.

\section{Conclusões}

Na busca de espaços profissionais para o desenvolvimento de suas carreiras e na ausência de um mercado ainda altamente competitivo, como na Europa, de onde a maioria dos diretores estrangeiros dos museus latino-americanos veio, eles próprios se intercambiaram na direção de instituições, quer em um mesmo país, ou transferindo sua experiência de um país para outro. Assim é que Emil Goeldi e Hermann von Ihering, a princípio naturalistas viajantes do Museu Nacional do Rio de Janeiro, tornaram-se diretores de seus próprios museus, respectivamente na Amazônia e em São Paulo. Emilia Snethlage - ornitóloga alemã, que foi a primeira mulher a dirigir um museu na América Latina, seguiu um caminho inverso. Deixou o Museu Paraense, o qual dirigiu durante o período da Primeira Guerra Mundial, e tornou-se naturalista do Museu Nacional do Rio de Janeiro.

Ameghino colaborou na organização de praticamente todos os museus argentinos - La Plata, Córdoba, Paraná -, antes de conseguir se tornar o diretor do Museu Nacional de Buenos Aires. No Chile, o zoólogo inglês Edwyn Reed dirigiu o Museu de Valparaíso, fundado em 1876. Foi entomólogo do Museu Nacional do Chile, e posteriormente criou e dirigiu o museu de Concepción (1903). Carlos Porter, de Valparaíso foi para o Museu Nacional de Santiago até a reorganização do Museu de Valparaíso, que havia sido destruído por um terremoto em 1906. Carlos Berg, que já era funcionário do Museu de Buenos Aires, dirigiu por dois anos o Museu Nacional de Montevidéu, antes de se tornar o sucessor de Burmeister e voltar a Buenos Aires. O suíço Henri Pittier participou da organização de museus na Costa Rica e na Venezuela.

Na verdade, esses intercâmbios foram em muitos casos determinados pelas próprias relações que se estabeleciam entre os pesquisadores europeus que viviam na América Latina; pelos ambientes naturais de estudos que as fronteiras políticas entre os países não dividiam, bem como pelos interesses científicos que partilhavam. Os alemães de São Paulo, Buenos Aires, Santiago mantiveram-se em contato constante. A flora, a fauna e a mineralogia andinas uniram pesquisas no Equador, Peru e Chile. A paleontologia das antigas conexões faunísticas fortaleceu os laços entre os museus Paulista, de Montevidéu, Buenos Aires e Santiago.

Estas relações entre esses diretores dos museus fizeram parte da dinâmica regional latino-americana do processo de mundialização da ciência, ao lado das 
exposições e congressos científicos que se iniciaram no final do século e de outras formas de intercâmbio que se consolidaram. E esses intercâmbios foram, em muitos casos, determinados pelas próprias relações que se estabeleciam entre os pesquisadores europeus que viviam na América Latina; pelos ambientes naturais de estudos que as fronteiras políticas entre os países não dividiam, bem como pelos interesses pessoais e científicos que partilhavam.

\section{REFERÊNCIAS}

ALVES,A. M. de A. Um museu científico na bistória de São Paulo: o Museu do Ipiranga. 1998. $207 \mathrm{f}$. Dissertação (Mestrado) - Faculdade de Filosofia, Letras e Ciências Humanas, Universidade de São Paulo, São Paulo, 1998.

BARNES, B. Sobre ciencia. Barcelona: Ed. Labor. 1987.

BREFE, A. C. F. Um lugar de memória para a Nação. O Museu Paulista reinventado por Affonso d’Esgragnolle Taunay (1917-1945). 1999.304 f.Tese (Doutorado) - IFCH, Universidade de Campinas, Campinas, 1999.

DERBY,O.A. Retrospecto histórico dos trabalhos geographicos e geologicos effectuados na Provincia de São Paulo. Boletim da Commissão Geographica e Geologica da Provincia de São Paulo, n.1, 1889. 26p.

DIBON, P.Les échanges épistolaires dans l'Europe savante du XVIIe siècle. Paris, Révue de Syntbèse, Tomo XCVII, n. 81-82, p. 31-50, jan.-juin. 1976.

ELIAS, M. J. Museu Paulista: memória e História. 1996. 473 f. Tese (Doutorado) - Faculdade de Filosofia, Letras e Ciências Humanas, Universidade de São Paulo, 1996.

FIGUEIRÔA, S. F. de M. Ciência na busca do eldorado:a institucionalização das ciências geológicas no Brasil, 1808-1907. 1992. 171 f. Tese (Doutorado) - Faculdade de Filosofia, Letras e Ciências Humanas, Universidade de São Paulo, 1992.

FIGUEIRÔA, S. F. de M.As ciências geológicas no Brasil: uma história social e institucional, 18751934. São Paulo: Hucitec, 1997.

FIGUEIRÔA, S. F. de M..The writings of Orville Adelbert Derby (1851-1915) and its meaning to the history of geological sciences in Brasil. In: INT.SYMP.HIST. OF GEOL. SCIENCES, 16., 1991, Dresden. Abstracts... Dresden:INHIGEO, 1991.p. 19-20.

FOX, R.;WEISZ, G. Introduction:The institutional basis of French science in the nineteenth century. In: ___ The organization of science and technology in France 1808-1914. Cambridge: Cambridge University Press, 1980.p.15.

GOHAU, G. História da geologia. Tradução de Carmen de Carvalho. Portugal: Publ. Europa-América, [s. d.]. 204 p. (Forum da Ciência, 2). 
GUALTIERI, R.C.E.Evolucionismo e ciência no Brasil:museus, pesquisadores e publicações, 18701915. São Paulo: FFLCH, 2001.

IHERING,H. Bibliografia. Os museus daAmerica do Sul. Revista do Museu Paulista, v.I,p. 233-245, 1895.

LOPES, M. M.As ciências naturais e os museus no Brasil no século XIX.1993.361 f.Tese (Doutorado)

- Faculdade de Filosofia, Letras e Ciências Humanas, Universidade de São Paulo, São Paulo, 1993.

LOPES, M. M. O Brasil descobre a pesquisa cientifica: os museus e as ciências naturais no século XIX . São Paulo: Hucitec. 1997.

LOPES, M. M.; FIGUEIRÔA, S. F. de M.Apresentação. Relatório FAPESP: Emergência e consolidação das ciências naturais no Brasil (1780-1870). Proc. n. 2.000/04751-0 (set de 2000- dez de 2002)

LOPES, M. M.; FIGUEIRÔA, S. F. de M.. Reactions to continental drift in Brazil in the beggining of the $20^{\text {th }}$ century. In:INT. SYMP.HIST.GEOL. SCIENCES, 15., 1990, Pequim. Abstracts... Pequim:INHIGEO, 1990. p. 41-42.

LOPES, M. M.;FIGUEIRÔA, S.F.de M.Horizontal interchanges in geological sciences. In:BRANAGAN, D. F; McNALLY, G. H. (Org.). Useful and curious geological enquiries beyond the world (PacificAsia bistorical themes). Sidney: INHIGEO, 1994. p. 1-6.

MENESES, U. B. de A problemática da identidade cultural nos museus: do objetivo (de ação) a objeto (de conhecimento). Anais do Museu Paulista, n.1, p. 207-222, 1993.

MENESES, U. B. de Do teatro da memória ao laboratório da História.A exposição museológica e o conhecimento histórico.Anais do Museu Paulista, v. 2, p. 9-42, 1994.

MENESES, U. B. de Museu Paulista. Estudos Avançados, v. 8, n. 22, p. 573-578, 1994.

OUTRAM,D.The letters of Georgers Cuvier. A summary calendar of manuscript and printed materials preserved im Europe, the United States of America, and Australasia. London: BSHS, 1980.

PODGORNY, I. "De la santidad laica del científico. Florentino Ameghino y el espectáculo de la ciencia en la Argentina moderna”. Entrepasados, Buenos Aires, v. 13, p. 31-67, 1997.

RIBEIRO, A Em defesa do dr. Hermann von Ibering. Secção de Obras do "Estado de São Paulo", 1916.

TORCELLI,A.J.(Org.).(1913-1937) Obras Completas y Correspondencia Científica de Florentino Ameghino. La Plata:Taller de Impresiones Oficiales, 1936. $23 \mathrm{v}$.

TURNER, F. M. Public science in Britain, 1880-1919. ISIS, v. 71, n. 259, p. 589-609, 1980.

Artigo apresentado em 8/2003. 


\section{RESUMOS/ABSTRACTS}

Um museu para o século XXI: o Museu Paulista e os desafios para os novos tempos

\section{Raquel Glezer}

Este texto explora o conhecimento sobre o Museu Paulista, em seus dois prédios, em São Paulo e em Itu: o que é em nossos dias; como foi criado e transformado em Museu de História; o conteúdo histórico que aparece em seu interior como passado materializado; os contextos históricos, nacional e internacional, que não estão citados; as demandas sociais atuais e a necessidade de projeto para o futuro.

PALAVRAS-CHAVE: Museu Paulista. História.Análise Historiográfica.

Anais do Museu Paulista. São Paulo. N. Sér.v. 10/11. p.9-21 (2002-2003).

A museum for the $21^{\text {st }}$ century: Museu Paulista and the challenges for the new times

\section{Raquel Glezer}

This essay peers into the knowledge about Museu Paulista, in its two buildings, in São Paulo and ltu: what is it in our days; how it was created and transformed into a History museum; the historical contents shown within its walls as a materialized past; the historical, national and international contexts, which are not cited; the actual social demands and the need of a project for the future.

KEYWORDS: Museu Paulista. History. Historiography analysis.

Anais do Museu Paulista. São Paulo. N. Sér.v. 10/11.p.9-21 (2002-2003).

A criação do Museu Paulista na correspondência de Hermann von Ihering (1850-1930)

Maria Margaret Lopes, Silvia Fernanda de Mendonça Figueirôa

Este artigo discute aspectos da organização inicial do Museu Paulista a partir das correspondências de Hermann von lhering com o geólogo Orville A. Derby e o paleontólogo Florentino Ameghino. Considera a discussão sobre a origem do Museu Paulista no contexto dos processos de consolidação das ciências naturais no Brasil. Estes foram marcados, no final do século XIX, pelas disputas por espaços de profissionalização, que ultrapassavam os limites do território nacional. Discute ainda o peso do entrelaçamento das iniciativas de caráter claramente individual nos processos oficiais de criação de loci institucionais para a pesquisa.

PALAVRAS-CHAVE: Museu. Museu Paulista. Museu de História Natural. Ciências Naturais

Anais do Museu Paulista. São Paulo. N. Sér. v. 10/11.p.23-35 (2002-2003).

The creation of Museu Paulista in the correspondence of Hermann von Ihering (1850- 1930)

Maria Margaret Lopes, Silvia Fernanda de Mendonça Figueirôa

This essay discusses some aspects of Museu Paulista's initial organization based on Hermann von Ihering's correspondence with the geologist Orville A Derby and the paleontologist Florentino Ameghino. It considers the discussion on the origins of Museu Paulista within the context of the processes of consolidation of Natural Sciences' in Brazil. In the end of the 19th century, these processes were characterized by disputes for profession-teaching spaces that went beyond national boundaries. It also deals with the weight of the clearly personal-characterized initiatives webbing in the official processes leading to the creation of institutional loci for research.

KEYWORDS: Museum. Museu Paulista. Natural History Museum. Natural Sciences. 